\title{
Scaling the Effectiveness of Existing Compressive Sensing in Multimedia Contents
}

\author{
Lakshminarayana. M \\ Research Scholar, \\ Department of ECE \\ VTU Research Resource Centres \\ Belgaum-590018, India
}

\author{
Mrinal Sarvagya, Ph.D. \\ Professor and Head, \\ School of ECE \\ REVA University \\ Bangalore-560064, India
}

\begin{abstract}
Compression has always played a crucial role in storage and transmission of heavier multimedia files. The existences of compression algorithms are more than two decade old. The normal compression algorithms are sometimes not required to process a signal in many cases where the signals are sparse. In such cases, compressive sensing highly contributes and compensates the issues of conventional compression algorithms as it performs sampling as well as compression at a same time. The concept of compressive sensing is quite new and is not much in matured stage. Our findings reported in this paper is a result of observation being carried out on all major research journals, which states that there are little amount of studies being done on compressive sensing and reconstruction of multimedia contents. The paper also discusses about the significant research gap and evaluates teh effectiveness of existing techniques.
\end{abstract}

\section{Keywords}

Compressive Sensing, Compressive Sampling, Compression, Multimedia, Lossless.

\section{INTRODUCTION}

With the advancement of networking and communication system, users finds it much accessible to sharing process of various digital contents. Out of all the digital contents, multimedia contents are something which are massively high in use by the users. Usually, multimedia files are quite heavier and it consists of image, video, and signals in its domain of study. As multimedia files are heavier, it is essential that the signals should be captured effectively as well as it should be compressed effectively. In the traditional image processing, an image is usually sampled first at maximum rate and then the conventional compression techniques (e.g. DCT) is applied through JPEG standards in order to ensure optimal storage [1]. However, such principles find it quite challenging in presence of imaging devices with poor resolution as well as constraint energy availability and computational potentials. Hence, the area of compressive sensing has come as a boon to solve this problem. This technique of compressive sensing is mainly investigated for its unique capabilities of performing compression and sampling at a same time [2]. Various theories till date have claimed that in order to perform reconstruction of a signal, a minimal set of measurement is required. The principle of compressive sensing furnishes the optimal minimization of the rate of sampling, complexities pertaining to computation, and energy dissipation. Fig.1 shows the process of compressed sensing where the signal is compressed and sensed together. Summation of voltages of arbitrarily selected pixels are done with sparsity matrix. The process only performs a summed value to be digitized which makes the compressed image. However, the process is not that
Easy as it seems like as till date majority of the existing research work focusing on compressive sensing is more or less a hypothetical study with less scope of applicability in real-time applications. There are some of the potential pitfalls of the compressive sensing as there is lack of minimal structures in the image that is reconstructed as well as poor resolution of degraded image [3]. Existing techniques of using total variation that is found frequently to be adopted in compressive sensing needs less number of iterations.
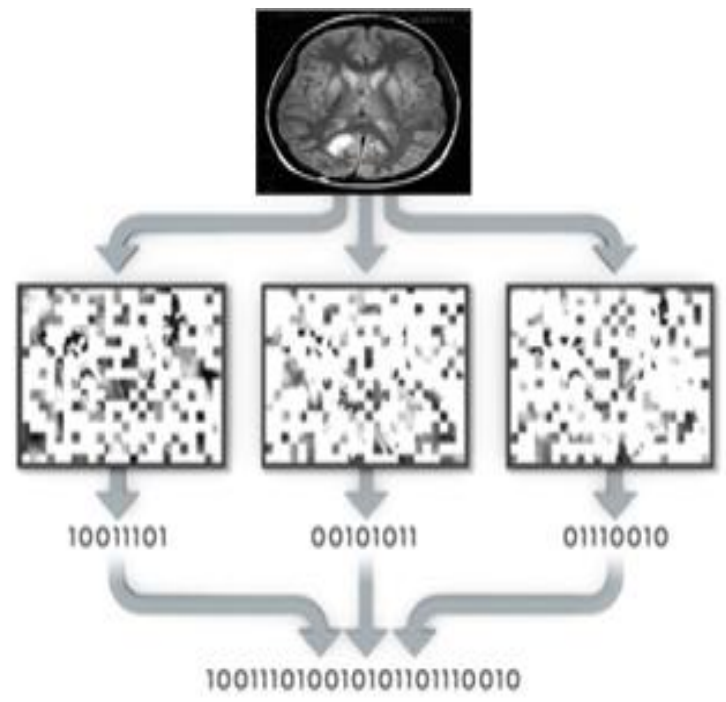

Figure.1. Process of Compressive Sensing

The area of compressive sensing is used in applied mathematics as well as majorly in signal processing. It has been also used in image processing especially in radar images, medical images, and aerial images. The prime contribution of this paper is to perform review of existing survey papers and majorly into existing research techniques in compressive sensing. The paper tries to find research gap in the existing system. Section 2 discusses about the essentials of the compressed sensing followed by existing survey on Section 3 . Section 4 enlists about the existing techniques for performing compressive sensing in image, video, and speech. Section 5 discusses about the research gap followed by Section 6 that discusses about conclusion.

\section{COMPRESSED SENSING ESSENTIALS}

In the area of signal processing, compressed sensing is considered as one of the significant technique for extracting and reconstructing a signal by exploring the solution to underdetermine significant linear systems. The theory of compressive sensing has evolved owing to the issues in 
imaging speed that is specifically important in applications related to medical signal processing (Fig.3). There are various physiological as well as physical constraints that significantly affects the process of data collecting in medical signal processing applications. Therefore, it is important that an efficient technique be explored that can minimize the amount of extracted data without any significant impact on quality of a signal. Therefore, owing to under-sampled kspace, the criterion of Nyquist's is violated and moreover there are increasing evidences of artifacts in Fourier reconstruction process.

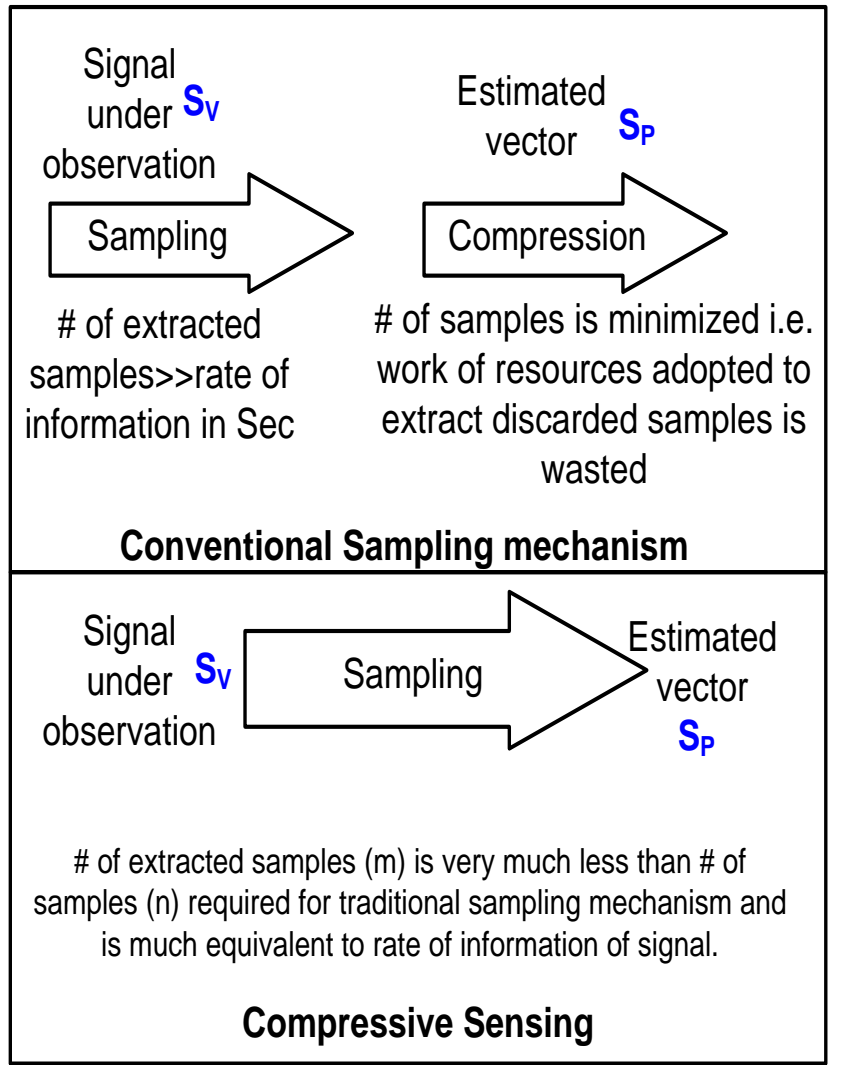

Figure.2. Conventional Sampling and Compressing Sensing

Fig.2 exhibits the conventional sampling of data as well as compressing sensing. Hence, the theory states that it is possible to extract a signal from minimal samples; however, the extraction of the signal can be $100 \%$ successful if the signal is being captured a minimal rate of information. This concept foretells that the signal is originally a sparse or belongs to some other form of transform domain. Hence, certain definitions are important to be highlighted to understand compressive sensing as:

- Sparsity: Various conventional forms of signals (image, audio, seismic data etc.) are reposited in compressed mode on the basis of suitability or the projection. It was found that after selecting the basis, a maximal quantity of the projection coefficients are usually found to be zero or very small values that are usually neglected. Hence, the theory states that if the signal has n-number of nonzero coefficient, that signal is said to be n-sparse. The theory also states that if maximal quantities of the coefficient of projection are minimal enough to be neglected, then only the signal can be subjected to compression algorithms.
- Incoherence: It is a statistical quantity that evaluates the highest correlation between any two elements from two different matrices. If $\theta$ is considered to be square matrix of size $\mathrm{n}$ with $\theta 1, \theta 2$, .... $\theta$ n columns and $\Omega$ is a non-square matrix of size $\mathrm{m} \times \mathrm{n}$ with $\Omega 1, \Omega 2, \ldots . \Omega \mathrm{m}$ as rows, than the mathematical interpretation of coherence $\sigma$ is:

$$
\sigma(\Omega, \theta)=\sqrt{n} \cdot \max \left|\Omega_{k}, \theta_{j}\right|
$$

Where the value of $\mathrm{j}$ lies between 1 to $\mathrm{n}$ and value of $\mathrm{k}$ lies between 1 and $\mathrm{m}$. Hence, according to linearity principle, the formulates:

$$
1 \leq \sigma(\Omega, \theta) \leq \sqrt{n}
$$

Therefore, from the domain viewpoint of compressive sensing, the focus is much on the matrix incoherence factor adopted in sampled or in sensed signal $\Omega$ as well as the matrix that represents the basis where there is a sparse signal of interest $\theta$.

- Signal Extraction: The process of extracting the signal in compressive sensing is quite equivalent to traditional one. The mathematical interpretation can be laid for the process of sensing SP considering S as signal,

$$
S_{P}=\Omega \cdot S
$$

The signal S and signal process SP are usually represented by real number of dimension $n$ and $m$ respectively. The traditional sensing concepts says that $m$ should be equivalent to $n$ in case certain levels of presence of sparse signals or compressible signals. The minimal value of $\mathrm{m}$ is permissible for the sensing matrices that are found to be more incoherent within the original domain (or even in transform domain) where the signal is quite sparse. Hence, traditional sensing concepts uses Dirac delta functions while the problems is resisted by using Compressive sensing that considers random functions to speed up the process of signal extraction.

- Signal Reconstruction: Majority of the existing concepts uses non-linear techniques to reconstruct the original signals in compressive sensing that is dependent on knowledge of basis of representation with a possibility of either compressible or sparse signals. Hence, the basis of representation of signal $\mathrm{S}$ is,

$$
\theta S_{v}=S
$$

In the above equation, $\mathrm{Sv}$ is the sparse vector that represents coefficient of project of $S$ and $\theta$. The vector for measurement SP can be now represented as,

$$
S_{P}=\gamma S_{v}
$$

The above equation shows $\gamma$ as matrix of reconstructed signal which is equivalent to $\Omega . \theta$ and is of size $\mathrm{m} \mathrm{x} \mathrm{n}$. 


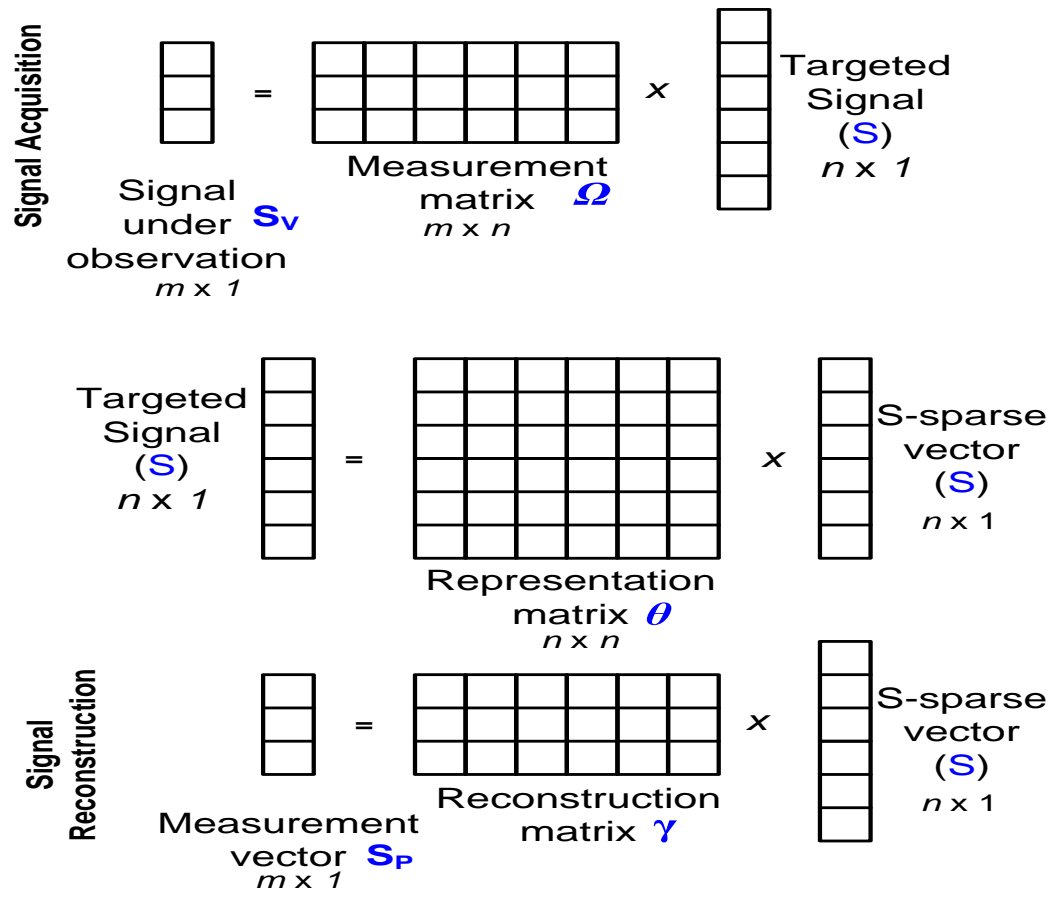

Figure.3. Signal Extraction and Reconstruction techniques in Compressive Sensing

\section{EXISTING SURVEY}

As the proposed study is mainly focused on reviewing the existing techniques and contributory studies discussed by prior literatures, it is very important for investigation that what is the existing status in the same domain? The adoption of compressive sensing is not new and it has been already adopted in the prior studies. There are various researchers who have used this technique on various problems domains of signal processing. Let us take a closer look into the existing status of the research paper, its year of publications, and the name of the publishers. So, we review the existing number of research papers and explored the effectiveness in them.

Table.1. Papers on Compressive Sensing techniques

\begin{tabular}{|c|c|c|c|}
\hline $\begin{array}{c}\text { Name of } \\
\text { Journals }\end{array}$ & From & To & $\begin{array}{c}\text { Journals } \\
\text { Published }\end{array}$ \\
\hline $\begin{array}{c}\text { IEEE } \\
\text { Xplore }\end{array}$ & 2006 & 2014 & 201 \\
\hline Elsevier & 2005 & 2015 & 81 \\
\hline Springer & 2006 & 2014 & 54 \\
\hline Hindawi & 2005 & 2015 & 48 \\
\hline IJCER & 2006 & 2014 & 42 \\
\hline IJSER & 2006 & 2014 & 25 \\
\hline IJARCCE & 2012 & 2014 & 16 \\
\hline IJERA & 2011 & 2015 & 42 \\
\hline
\end{tabular}

Table.2. Papers on Lossless Compression techniques

\begin{tabular}{|c|c|c|c|}
\hline $\begin{array}{c}\text { Name of } \\
\text { Journals }\end{array}$ & From & To & $\begin{array}{c}\text { Journals } \\
\text { Published }\end{array}$ \\
\hline $\begin{array}{c}\text { IEEE } \\
\text { Xplore }\end{array}$ & 2006 & 2015 & 235 \\
\hline Elsevier & 2005 & 2015 & 387 \\
\hline Springer & 2006 & 2014 & 470 \\
\hline Hindawi & 2005 & 2015 & 29 \\
\hline IJCER & 2006 & 2014 & 32 \\
\hline IJSER & 2005 & 2015 & 200 \\
\hline IJARCCE & 2012 & 2014 & 34 \\
\hline IJERA & 2011 & 2015 & 88 \\
\hline
\end{tabular}

Table 1 and Table 2 show the total number of the implemented research papers towards usual and lossless compression techniques. For generalized view, we choose to select the cumulative research papers from all the available journal publishers who support publication of compression techniques in signal processing domain. Table 1 shows that both the techniques have approximately more than 200 implementation papers on algorithms during the year 20062014. However, things are quite different in Elsevier, which was seen with 387 implementation papers on lossless compression techniques whereas there are only 81 implementation papers on compressive sensing techniques in 2005-2015. Almost the similar type of trends is observed for other journals too, which showcase that there are comparatively less implementation papers on compressive sensing till date. A simple and cumulative calculation for 
number of implementation papers for lossless compression scheme shows $(235+387+470+29=) 1121$ number of papers published during 2005-2015 (Table.2), while cumulative calculations for number of implementation papers for compressing sensing are found to be only $(201+81+54+48=)$ 384 (Table 1). The calculations are done for only ISI indexed journals like IEEEXplore, Elsevier, Springer, and Hindawi only. This simple calculations itself shows that there are only 384 research papers in ISI index journals on compressive sensing while there exists 1121 journals on lossless compression techniques.

Table.3. Total Survey papers on Compressive Sensing techniques

\begin{tabular}{|c|c|c|}
\hline $\begin{array}{c}\text { Name of } \\
\text { Journals }\end{array}$ & Year & $\begin{array}{c}\text { Published } \\
\text { Papers }\end{array}$ \\
\hline IEEE Xplore & $2007-2014$ & 12 \\
\hline IJCER & $2008-2014$ & 3 \\
\hline IJSER & $2011-2014$ & 9 \\
\hline IJARCCE & $2011-2014$ & 4 \\
\hline IJERA & $2011-2014$ & 6 \\
\hline Hindawi & $2011-2014$ & 3 \\
\hline ISRN & $2011-2014$ & 2 \\
\hline IJEIAE & $2011-2014$ & 1 \\
\hline IJESIT & $2012-2014$ & 1 \\
\hline IJCSA & $2012-2014$ & 1 \\
\hline IJSRP & $2012-2014$ & 1 \\
\hline RJASET & $2012-2014$ & 45 \\
\hline IJCA & $2012-2014$ & 1 \\
\hline & & \\
\hline
\end{tabular}

Table 3 shows the total number of survey papers published from 2007 to till date. As survey paper on compressive sensing beyond 2006 is very much insignificant and hence ignored. Our investigation shows that there are total of 45 survey papers on compressive sensing, while ISI index Journals like IEEE and Hindawi are found to have only 12 and 3 survey papers till date. Next, we filter the 16 most significant papers out of these 45 total published survey papers and attempted to find the effectiveness of the existing survey papers. In the year 2010, Berger et.al [4] have published a survey paper towards compressive sensing exclusively focusing on the sparse channel estimation. Along with the theory, the author has discussed the conventional algorithms e.g. convex and greedy type towards sparse multipath channels. Similar type of study has also being done by Gilbert and Indyk [5] in same year. A unique survey study was found in same year by Potter et.al [6] who have investigated the techniques of sparse reconstruction towards radar imaging. Tropp and Wright [7] have also investigated the sparse approximation techniques. The authors have discussed the conventional algorithms e.g. convex relaxation, greedy pursuits, Bayesian, brute force etc., and also discussed various algorithms of pursuits. Patel and Chellappa [8] have presented a discussion paper towards compressive sensing and spare representation.

In 2011, Wang [9] have presented an editorial for compressive sensing with an exclusive focus on medical image processing. In 2012, Dias and Bandewar [10] have published a survey paper on compressive sensing and discusses the existing trends in it with respect to signal processing. In same year Mammeriet. al. [11] have presented a review paper on image compression techniques exclusively considering sensor networks. The authors have discussed various compression schemes and finally discussed on effective principles on compression for sensor networks.

In 2013, Hayashi et al. [12] have presented a survey paper with focus on design and development of sensing matrix and sparsity aspects in compressed sensing. In same year, Kaur et. al. [13] have presented a review paper on reconstruction techniques. However, the study didn't significantly yield any potential findings towards compressive sensing. Ender [14] have performed a study, which is almost similar to review work done by Potter et. al. [6]. Pudlewski and Melodia [15] have discussed on various impediments towards multimedia transmission with respect to compressive sensing. Qaisar et. al. [16] have presented a discussion on pathway of compressive sensing from hypothetical approach to practical approach. Subban et. al. [17] have investigated the algorithms for sparse representation and compressed tracking. In 2014, Zhou and Zhou [18] have presented an article on compressive sensing that are adaptable in multimedia coding. Same year, Ali [AR] have surveyed some of the techniques of compressive sensing pertaining to localization.

Hence, it can be seen that in last decade there are 45 sets of survey work being published, out of which, we choose to discuss 16 survey papers. Table 4 will summarize these 16 surveypapers.

Table 4 existing Survey on Compression techniques

\begin{tabular}{|c|c|c|c|}
\hline Authors & Problem Focused & Informative factor & Limitation \\
\hline $\begin{array}{c}\text { Berger [4]- } \\
2010\end{array}$ & $\begin{array}{c}\text { Algorithms for sparse channel } \\
\text { estimation }\end{array}$ & Discussion on empirical aspects & $\begin{array}{c}\text { No discussion of prior research } \\
\text { attempts }\end{array}$ \\
\hline $\begin{array}{c}\text { Gilbert [5]- } \\
2010\end{array}$ & $\begin{array}{c}\text { Sparse recovery using sparse } \\
\text { random matrices. }\end{array}$ & Techniques for-each guarantee & $\begin{array}{c}\text { Performance effectiveness at } \\
\text { techniques not discusses. }\end{array}$ \\
\hline $\begin{array}{c}\text { Potter [6]- } \\
2010\end{array}$ & $\begin{array}{c}\text { sparse reconstruction towards } \\
\text { radar imaging }\end{array}$ & Algorithms for sparse reconstruction & Only theoretical illustrations. \\
\hline
\end{tabular}




\begin{tabular}{|c|c|c|c|}
\hline $\begin{array}{l}\text { Tropp [7]- } \\
2010\end{array}$ & Sparse approximations. & Algorithms on pursuit techniques & $\begin{array}{l}\text { No comparative evaluation } \\
\text { being conducted }\end{array}$ \\
\hline $\begin{array}{l}\text { Patel [8]- } \\
\quad 2011\end{array}$ & $\begin{array}{l}\text { Compressive sensing for Pattern } \\
\text { recognition }\end{array}$ & Dictionary methods & $\begin{array}{l}\text { Practically reviewed only } 5 \\
\text { implementation work }\end{array}$ \\
\hline $\begin{array}{l}\text { Wang [9]- } \\
\quad 2011\end{array}$ & $\begin{array}{c}\text { Compressive sensing for medical } \\
\text { imaging. }\end{array}$ & Existing studies on compressive sensing & $\begin{array}{l}\text { No comparative evaluation } \\
\text { being conducted }\end{array}$ \\
\hline $\begin{array}{l}\text { Dias [10]- } \\
\quad 2012\end{array}$ & Compressive sensing & Usage of transform techniques & $\begin{array}{l}\text { Practically reviewed only } 4 \\
\text { implementation work. }\end{array}$ \\
\hline $\begin{array}{l}\text { Mammeri } \\
{[11]-2012}\end{array}$ & $\begin{array}{l}\text { Image compression techniques in } \\
\text { sensor networks }\end{array}$ & Discussed on compression algorithms & $\begin{array}{l}\text { No discussion on Research } \\
\text { gap, less focus on CS }\end{array}$ \\
\hline $\begin{array}{l}\text { Hayashi } \\
{[12]-2013}\end{array}$ & Compressed sensing in signals & $\begin{array}{c}\text { Discussion algorithms e.g. FISTA (Fast } \\
\text { Iterative Shrinkage-Thresholding Algorithms), } \\
\text { NESTA (Nesterov's Algorithm) }\end{array}$ & Only theoretical illustrations. \\
\hline $\begin{array}{l}\text { Kaur [13]- } \\
\quad 2013\end{array}$ & Reconstruction techniques & Simplified techniques of compressive sensing & $\begin{array}{l}\text { Practically reviewed only } 5 \\
\text { implementation work }\end{array}$ \\
\hline $\begin{array}{l}\text { Ender [14]- } \\
\quad 2013\end{array}$ & $\begin{array}{c}\text { Compressed sensing in Radar } \\
\text { imaging }\end{array}$ & Enriched theoretical discussion on domains & Only theoretical illustrations. \\
\hline $\begin{array}{l}\text { Pudlewski } \\
{[15]-2013}\end{array}$ & $\begin{array}{l}\text { Challenges in compressive } \\
\text { imaging }\end{array}$ & $\begin{array}{l}\text { Discussed various techniques reconstruction in } \\
\text { compressive techniques }\end{array}$ & No discussion on Research gap \\
\hline $\begin{array}{l}\text { Qaisar [16]- } \\
\quad 2013\end{array}$ & $\begin{array}{l}\text { Compressive Sensing and } \\
\text { reconstruction algorithms }\end{array}$ & Reconstruction techniques & $\begin{array}{l}\text { Studied complexity of } 11 \\
\text { implementation studies. }\end{array}$ \\
\hline $\begin{array}{l}\text { Subban [17]- } \\
\quad 2014\end{array}$ & $\begin{array}{l}\text { Real time compressive tracking } \\
\text { methods. }\end{array}$ & Sparse representation techniques & $\begin{array}{l}\text { No discussion on Research } \\
\text { gap, Only theoretical } \\
\text { illustrations. }\end{array}$ \\
\hline $\begin{array}{l}\text { Zhou [18]- } \\
\quad 2014\end{array}$ & $\begin{array}{c}\text { Brief overview of CS video } \\
\text { coding. }\end{array}$ & Applications, literature review. & $\begin{array}{l}\text { Performance effectiveness at } \\
\text { techniques not discusses. }\end{array}$ \\
\hline $\begin{array}{l}\text { Ali [19]- } \\
\quad 2015\end{array}$ & $\begin{array}{l}\text { Discuss different present } \\
\text { techniques for localization of } \\
\text { user through CS. }\end{array}$ & $\begin{array}{l}\text { Literature review, comparison between CS and } \\
\text { DS, graphs. Different techniques with issue } \\
\text { and parameters. }\end{array}$ & $\begin{array}{l}\text { Less Significant discussion on } \\
\text { effectiveness of compressive } \\
\text { sensing }\end{array}$ \\
\hline
\end{tabular}

\section{EXISTING TECHNIQUES FOR COMPRESSIVE SENSING}

In last decade there are various studies that have been focusing on implementing the compressive sensing towards various kinds of multimedia contents. Hence, from total of 384 studies, we have filtered it to study more specifically. We siphoned out 11 implementation papers each toward compressive sensing on images, videos, and speech respectively. Performing compression on image is completely different as compared to video or speech. The signaling properties of image, video, as well as speech are completely different; however, there are some similarities too. Although compressing an image is no more a novel idea in research community, but performing compressive sensing of an image is quite less. All the techniques discussed in Table 5 uses the common step of compressive sensing e.g. i) developing a signal with sparse matrix, ii) designing an algorithm for compressing a sparse signal, and iii) finally performing reconstruction of the compressed signal. The common cases under consideration in existing techniques are presence of noise (especially Gaussian) during transmission effecting the compressed signals. All the techniques are more or less focuses on effective reconstruction process using the signal that is compressed. Similarly video compression mainly aims to minimize the data redundancy by integrating time-based motion compensation with distance based image compression. The adoption of source coding is very high in video compression but adoption of compressive sensing in video contents results in drastic degradation of video quality during reconstruction process. Hence, reconstructing a video file is quite challenging as compared to image file. However, adoption of compressive sensing also results in promising resiliency to channel errors. Such techniques uses both time and distance based correlation factor between the frames and coding is performed. Similarly performing compression of speech data has completely different complexity as compared to image and video. There is a various range of complexity in performing compressive sensing on speech signals, which is majorly sparse type. As human speech discontinues so it can be considered as sparse signals. However, there is a very less focus or research attempts being done in performing compressive sensing on speech signals. However, majority of the techniques adopted till date considers compressive sensing 
as a best mechanism to mitigate sparsity in signals as well as noise. In discussion of the sparsity, majority of the techniques tabulated in this section considers approximation in sparsity. However, specifically in video, compressive sensing is implemented as a part of encoder. Table 5, Table 6, and Table 7 discusses about the existing techniques of compressive sensing on image, video and speech. The discussion has been carried out with respect to problems that the researchers have focused, techniques that the researchers have used to mitigate the problems, and inference of the study is made with an aid of performance parameters too. Hence, out of 384 research papers, we have filtered out the best 33 papers, where the research contribution is found to be comparatively better than rest of the papers and it is tabulated.

Table.5. Summary of CS Techniques of Prior Researchers on Images

\begin{tabular}{|c|c|c|c|c|}
\hline Authors & Problem Focused & Techniques & Perform Param & Limitation \\
\hline Han [20]-2008 & $\begin{array}{l}\text { To remove dense \& sparse } \\
\text { components, to get better } \\
\text { reconstruction of image }\end{array}$ & $\begin{array}{l}\text { Compressive sensing } \\
\text { (CS), Projection onto } \\
\text { convex set (POCS) }\end{array}$ & $\begin{array}{l}\text { Rate distortion, } \\
\text { PSNR, Total error. }\end{array}$ & Computationally complex. \\
\hline Ma [21]-2008 & $\begin{array}{l}\text { To get better reconstruction, } \\
\text { minimize non-smooth } \\
\text { functions on large data sets }\end{array}$ & $\begin{array}{l}\text { Total Variation (TV), } \\
\text { L1-minimization, } \\
\text { Wavelets. }\end{array}$ & SNR, Relative error. & $\begin{array}{l}\text { Need better quality of } \\
\text { image, less Storage. }\end{array}$ \\
\hline $\begin{array}{l}\text { Nagesh [22]- } \\
2009\end{array}$ & $\begin{array}{l}\text { To recognize \& recover the } \\
\text { expression of invariant faces } \\
\text { with feature extraction. }\end{array}$ & Compressive sensing. & $\begin{array}{l}\text { Less storage space, } \\
\text { recognition rate. }\end{array}$ & $\begin{array}{c}\text { Need to use multiple views } \\
\text { of the scene. }\end{array}$ \\
\hline $\begin{array}{l}\text { Schulz [23]- } \\
2009\end{array}$ & $\begin{array}{c}\text { Signal acquisition \& } \\
\text { compression and perform } \\
\text { analysis of rate-distortion. }\end{array}$ & $\begin{array}{l}\text { L1-norm minimization } \\
\text { using (TV, SVD). }\end{array}$ & $\begin{array}{l}\text { PSNR, reducing } \\
\text { quantization step, } \\
\text { approximation error. }\end{array}$ & Outcome not benchmarked \\
\hline $\begin{array}{l}\text { Wright [24]- } \\
2009\end{array}$ & $\begin{array}{l}\text { Automatically to recognize } \\
\text { human faces with invariant } \\
\text { expression from frontal views } \\
\& \text { illumination, as well as } \\
\text { occlusion \& disguise. }\end{array}$ & $\begin{array}{l}\text { Sparse Representation } \\
\text { via L1-minimization } \\
\text { techniques. }\end{array}$ & $\begin{array}{l}\text { Recognition rates, } \\
\text { Sparsity } \\
\text { Concentration Index } \\
\text { (SCI). }\end{array}$ & $\begin{array}{l}\text { Need object detection in } \\
\text { addition to recognitions. }\end{array}$ \\
\hline Yang [25]-2010 & $\begin{array}{l}\text { To perform fast signal } \\
\text { reconstruction using Fourier } \\
\text { data. }\end{array}$ & $\begin{array}{l}\text { RecPF-Reconstruction } \\
\text { from Partial Fourier data }\end{array}$ & $\begin{array}{l}\text { Highly stable, } \\
\text { efficient and robust. } \\
\text { Relative error, } \\
\text { objection function. }\end{array}$ & $\begin{array}{l}\text { Computationally complex, } \\
\text { outcomes not benchmarked }\end{array}$ \\
\hline Sen [26]-2011 & $\begin{array}{l}\text { To reduce rendering rate by } \\
\text { using CS to find values of } \\
\text { unrendered pixels. }\end{array}$ & Compressive rendering & $\begin{array}{l}\text { MSE, high quality of } \\
\text { images, accurate } \\
\text { reconstruction. }\end{array}$ & $\begin{array}{c}\text { Needs at extremely low } \\
\text { sampling densities. (<5\% } \\
\text { of pixel samples), } \\
\text { outcomes not benchmarked }\end{array}$ \\
\hline Chen [27]-2012 & $\begin{array}{l}\text { To detect \& track objects in } \\
\text { motion with minimum number } \\
\text { of data samples. (for Video- } \\
\text { surveillance) }\end{array}$ & $\begin{array}{c}\text { A real time CS L1 } \\
\text { tracking, random } \\
\text { Gaussian or Toeplitz } \\
\text { phase. Motion detection } \\
\text { algorithms. }\end{array}$ & $\begin{array}{l}\text { High resolution, less } \\
\text { storage, better } \\
\text { reconstruction. Fast } \\
\text { tracking. }\end{array}$ & $\begin{array}{l}\text { Outcomes not } \\
\text { benchmarked }\end{array}$ \\
\hline $\begin{array}{l}\text { Sermwuthisarn } \\
\text { [28]-2012 }\end{array}$ & $\begin{array}{l}\text { To remove the effect of } \\
\text { Gaussian noise and get better } \\
\text { reconstruction of images. }\end{array}$ & $\begin{array}{l}\text { OMP-PKS+RS based on } \\
\text { Compressing sensing. }\end{array}$ & $\begin{array}{l}\text { PSNR, better Visual } \\
\text { quality, low } \\
\text { measurements. }\end{array}$ & $\begin{array}{l}\text { Need to improve } \\
\text { reconstruction for both } \\
\text { impulsive and Gaussian } \\
\text { noise. }\end{array}$ \\
\hline $\begin{array}{l}\text { Hemalatha [29]- } \\
2013\end{array}$ & $\begin{array}{l}\text { To analyze the energy } \\
\text { consumption to transmitting } \\
\text { image using CS with rate } \\
\text { distortions analysis. }\end{array}$ & $\begin{array}{l}\text { BinDCT + Noiselet } \\
\text { based on CS. }\end{array}$ & $\begin{array}{l}\text { PSNR, reduced bit } \\
\text { rate }(<0.5 \mathrm{bpp}), \\
\text { compression ratio, } \\
\text { Energy consumed. }\end{array}$ & $\begin{array}{c}\text { Still need to reduce energy } \\
\text { consumption }\end{array}$ \\
\hline Liu [30]-2013 & $\begin{array}{l}\text { To recover signals from sub- } \\
\text { Nyquist samples with CS for } \\
\text { Multiple structures of } \\
\text { biomedical signals. }\end{array}$ & $\begin{array}{l}\text { L1-TV, TV- } \\
\text { minimization, Nuclear } \\
\text { norm minimization. }\end{array}$ & $\begin{array}{l}\text { Mean L1 error, better } \\
\text { reconstruction } \\
\text { accuracy. }\end{array}$ & $\begin{array}{l}\text { Outcomes not } \\
\text { benchmarked }\end{array}$ \\
\hline
\end{tabular}


Multimedia compressive sensing (CS), another use of CS, has as of late been researched to catch rapid features at low edge rate by method for time-based compression. A shared trait of these multimedia CS frameworks is the utilization of every pixel adjustment amid one coordination time-period, to conquer the spatio-fleeting determination exchange off in feature catch. As an outcome of dynamic and inactive pixel level coding systems, it is conceivable to interestingly adjust a few transient edges of a consistent feature stream inside the
Time-scale of a solitary incorporation time of the camcorder (utilizing an ordinary cam). This allows these novel imaging architectures to keep up high determination in both the spatial and the fleeting areas. Each one low-speed presentation caught by such CS cams is a direct blend of the hidden coded rapid feature outlines. After obtaining, fast features are reproduced by different CS reversal calculations. These hardware based frameworks were initially intended for uniform time based compression ratio. Table 6 showcase video CS techniques.

Table.6. Summary of CS Techniques of Prior Researchers on Video

\begin{tabular}{|c|c|c|c|c|}
\hline Authors & Problem Focused & Techniques & Perform Param & Limitation \\
\hline $\begin{array}{l}\text { Pudlewski [31]- } \\
2010\end{array}$ & $\begin{array}{l}\text { To investigate the limits \& } \\
\text { outlines of video parameters } \\
\text { on the received video of CS } \\
\text { streams over multi-hop WSN. }\end{array}$ & $\begin{array}{l}\text { Adaptive Parity based } \\
\text { Channel coding. }\end{array}$ & $\begin{array}{c}\text { SSIM, BER, } \\
\text { Quantization rate, } \\
\text { image quality, low } \\
\text { degradation. }\end{array}$ & $\begin{array}{l}\text { Enhanced quality of } \\
\text { reconstructed } \\
\text { signal, Outcomes } \\
\text { not benchmarked }\end{array}$ \\
\hline Chaozhu [32]-2011 & $\begin{array}{c}\text { To reduce System } \\
\text { computational complexity \& } \\
\text { compression efficiency. }\end{array}$ & $\begin{array}{l}\text { Distributed video coding } \\
\text { based on CS, L1- } \\
\text { minimization. }\end{array}$ & $\begin{array}{l}\text { PSNR, quality, less } \\
\text { computational, } \\
\text { compression ratio. }\end{array}$ & $\begin{array}{l}\text { Not much } \\
\text { significant novelty }\end{array}$ \\
\hline $\begin{array}{l}\text { Pudlewski [33]- } \\
2011\end{array}$ & $\begin{array}{l}\text { To investigate rate of video } \\
\text { transmissions, low complexity } \\
\text { with limited budget of } \\
\text { available energy. }\end{array}$ & CS video encoder (CVS). & $\begin{array}{l}\text { SSIM, BER, SNR, } \\
\text { Encoded Video Rate, } \\
\text { Total Energy Budget. }\end{array}$ & $\begin{array}{l}\text { Mainly inclined on } \\
\text { using H.264 }\end{array}$ \\
\hline Mansour [34]-2012 & $\begin{array}{l}\text { estimate to focus the } \\
\text { measurements on the large } \\
\text { valued coefficients of a } \\
\text { compressible signal }\end{array}$ & $\begin{array}{c}\text { adaptive CS scheme, } \\
\text { weighted L1 minimization }\end{array}$ & SNR, QCIF & $\begin{array}{l}\text { Less extensive } \\
\text { outcomes analysis }\end{array}$ \\
\hline $\begin{array}{c}\text { Sankaranarayanan } \\
\text { [35]-2012 }\end{array}$ & $\begin{array}{c}\text { CS for Spatial-Multiplexing } \\
\text { Cameras }\end{array}$ & $\begin{array}{c}\text { CS multi-scale video, } \\
\text { Sensing and recovery } \\
\text { framework for SMCs, L1- } \\
\text { norm recovery }\end{array}$ & $\begin{array}{l}\text { Relative speed, frame } \\
\text { rate. }\end{array}$ & $\begin{array}{l}\text { Outcomes not } \\
\text { benchmarked }\end{array}$ \\
\hline Chen [36]-2013 & $\begin{array}{l}\text { To decrease signal power for } \\
\text { better transmissions, high loss } \\
\text { rate \& noise for heterogeneous } \\
\text { receiver. }\end{array}$ & $\begin{array}{l}\text { Enhanced compressed- } \\
\text { sensing-based wireless } \\
\text { video multicast }\end{array}$ & $\begin{array}{l}\text { PSNR, low complexity } \\
\text { encoding, better } \\
\text { transmission. }\end{array}$ & $\begin{array}{c}\text { Visual } \\
\text { perceptibility is less }\end{array}$ \\
\hline $\begin{array}{l}\text { Pudlewski-[37]- } \\
2013\end{array}$ & $\begin{array}{l}\text { To achieve better video } \\
\text { quality transmission and to } \\
\text { required transmission power } \\
\text { at the multimedia sensor node. }\end{array}$ & $\begin{array}{c}\text { Relay Assisted } \\
\text { Compressed Video Sensing }\end{array}$ & $\begin{array}{l}\text { SNR, MSE, SSIM, } \\
\text { good video quality. }\end{array}$ & $\begin{array}{l}\text { Minor enhancement } \\
\text { in PSNR only. }\end{array}$ \\
\hline $\begin{array}{l}\text { Pudlewski [38]- } \\
2013\end{array}$ & $\begin{array}{l}\text { To reduce energy, lack of } \\
\text { resilience to channel errors } \\
\text { and high computational } \\
\text { complexity. }\end{array}$ & $\begin{array}{l}\text { CVS, H.264AVC intra, } \\
\text { MJPEG. }\end{array}$ & $\begin{array}{l}\text { SSIM, good quality of } \\
\text { video, low energy } \\
\text { consumption per frame, } \\
\text { BER. }\end{array}$ & $\begin{array}{l}\text { Mainly focused on } \\
\text { H.264 and MJPEG } \\
\text { encoders, outcomes } \\
\text { were not found } \\
\text { benchmarked. }\end{array}$ \\
\hline Yuan [39]-2013 & $\begin{array}{l}\text { To estimate the motion of the } \\
\text { objects within the scene, to } \\
\text { adapt the compression ratio } \\
\text { for effective video capture. }\end{array}$ & $\begin{array}{c}\text { adaptive temporal } \\
\text { compressive sensing (CS) } \\
\text { for video, block-matching } \\
\text { algorithm }\end{array}$ & $\begin{array}{l}\text { PSNR, compression } \\
\text { ratio, }\end{array}$ & $\begin{array}{l}\text { seek to embed this } \\
\text { real-time } \\
\text { Framework into the } \\
\text { hardware prototype. }\end{array}$ \\
\hline Liu [40]-2013 & $\begin{array}{l}\text { a video system where } \\
\text { acquisition is carried out in } \\
\text { the form of direct compressive } \\
\text { sampling (CS) with no other }\end{array}$ & $\begin{array}{l}\text { Karhunen-Loeve bases } \\
\text { (KLT), K-SVD }\end{array}$ & $\begin{array}{l}\text { PSNR, reconstruction } \\
\text { quality. }\end{array}$ & $\begin{array}{l}\text { Doesn't support } \\
\text { efficient encoding } \\
\text { and decoding } \\
\text { scheme, doesn't }\end{array}$ \\
\hline
\end{tabular}




\begin{tabular}{|c|c|c|c|c|}
\hline & $\begin{array}{c}\text { form of sophisticated } \\
\text { encoding. }\end{array}$ & & $\begin{array}{c}\text { considered much on } \\
\text { recovery algorithms }\end{array}$ \\
\hline Iliadis [41]-2013 & $\begin{array}{c}\text { Video compressive sensing } \\
\text { (CS) framework based on the } \\
\text { Single Pixel Camera (SPC). }\end{array}$ & $\begin{array}{c}\text { Multiple Measurement } \\
\text { Vectors (MMV), SMV. }\end{array}$ & $\begin{array}{c}\text { Minor enhancement } \\
\text { in PSNR only, } \\
\text { should have } \\
\text { evaluated with } \\
\text { other datasets too. }\end{array}$ \\
\hline
\end{tabular}

Table.7. Summary of CS Techniques of Prior Researchers on Speech

\begin{tabular}{|c|c|c|c|c|}
\hline Authors & Problem Focused & Techniques & Perform Param & Limitation \\
\hline $\begin{array}{l}\text { Giacobello } \\
{[42]-2008}\end{array}$ & $\begin{array}{l}\text { Retrieving sparse patterns using CS } \\
\text { framework for speech. }\end{array}$ & CS, L0 normalization. & $\begin{array}{l}\text { Good perceptual } \\
\text { quality, normalized } \\
\text { error, }\end{array}$ & $\begin{array}{l}\text { Time and space } \\
\text { complexity not } \\
\text { discussed }\end{array}$ \\
\hline $\begin{array}{l}\text { Christensen } \\
{[43]-2009}\end{array}$ & $\begin{array}{l}\text { To sparse decompositions based on } \\
\text { dictionaries comprised of } \\
\text { windowed complex exponentials. }\end{array}$ & CS method. & $\begin{array}{l}\text { SNR, Power spectrum, } \\
\text { sparsity, }\end{array}$ & $\begin{array}{c}\text { Numerical } \\
\text { outcomes not } \\
\text { benchmarked }\end{array}$ \\
\hline $\begin{array}{l}\text { Masiero- } \\
{[44]-2010}\end{array}$ & $\begin{array}{c}\text { To estimate source radiation pattern } \\
\text { of sound sources with a reduced } \\
\text { number of sensors. }\end{array}$ & $\begin{array}{l}\text { L1 minimization method based } \\
\text { on CS. }\end{array}$ & $\begin{array}{l}\text { SNR, better quality of } \\
\text { audio signals. }\end{array}$ & $\begin{array}{l}\text { No effective } \\
\text { benchmarking }\end{array}$ \\
\hline $\begin{array}{l}\text { Griffin } \\
{[45]-2010}\end{array}$ & $\begin{array}{c}\text { Speaker identification using } \\
\text { sparsely excited speech signals. }\end{array}$ & $\begin{array}{l}\text { Least Absolute Shrinkage and } \\
\text { Selection Operator }\end{array}$ & SNR, power gain, & $\begin{array}{l}\text { Signal quality not } \\
\text { optimized }\end{array}$ \\
\hline $\begin{array}{l}\text { Asaei [46]- } \\
\quad 2011\end{array}$ & speech recognition from distance & $\begin{array}{c}\text { L1 minimization, Line } \\
\text { Orientation Separation } \\
\text { Technique }\end{array}$ & SNR, BSS-MSR. & $\begin{array}{l}\text { Less extent of } \\
\text { outcome } \\
\text { discussion }\end{array}$ \\
\hline $\begin{array}{l}\text { Tan [47]- } \\
2011\end{array}$ & $\begin{array}{c}\text { Speech recognition from anterior } \\
\text { end }\end{array}$ & $\begin{array}{l}\text { Least Angle Regression for } \\
\text { exploiting characteristics of } \\
\text { collinear dictionary }\end{array}$ & $\begin{array}{c}\text { SNR, degree of } \\
\text { sparsity, accuracy, }\end{array}$ & $\begin{array}{c}\text { Effect of } \\
\text { dimensionality } \\
\text { minimization was } \\
\text { not focused }\end{array}$ \\
\hline $\begin{array}{l}\text { Wang [48]- } \\
\quad 2011\end{array}$ & $\begin{array}{l}\text { Synthesizing speech signal } \\
\text { synthesis }\end{array}$ & $\begin{array}{l}\text { Orthogonal matching pursuits } \\
\text { algorithm, L0 norm } \\
\text { minimization. }\end{array}$ & $\begin{array}{l}\text { SSNR, high } \\
\text { compression ratio, } \\
\text { perceptual quality. }\end{array}$ & $\begin{array}{l}\text { No comparative } \\
\text { analysis }\end{array}$ \\
\hline $\begin{array}{l}\text { Feng [49]- } \\
2012\end{array}$ & $\begin{array}{l}\text { To enhance the signal quality of } \\
\text { speech }\end{array}$ & $\begin{array}{l}\text { adaptive compressive sensing } \\
\text { method }\end{array}$ & $\begin{array}{l}\text { SNR, better } \\
\text { reconstruction, }\end{array}$ & $\begin{array}{l}\text { Less effective } \\
\text { benchmarking }\end{array}$ \\
\hline $\begin{array}{l}\text { Hashim } \\
{[50]-2012}\end{array}$ & $\begin{array}{l}\text { To achieve better reconstruction of } \\
\text { sparse audio signals. }\end{array}$ & $\begin{array}{l}\mathrm{CS}, \mathrm{L} 1 \text { and L2 in sparse } \\
\text { domain. }\end{array}$ & $\begin{array}{l}\text { Quality of audio, better } \\
\text { reconstruction of audio } \\
\text { signals. }\end{array}$ & $\begin{array}{l}\text { Outcomes not } \\
\text { benchmarking }\end{array}$ \\
\hline $\begin{array}{l}\text { Lin }[51]- \\
2013\end{array}$ & $\begin{array}{l}\text { Compressed sensing of speech } \\
\text { signals in IPTV }\end{array}$ & $\begin{array}{l}\text { An acoustic echo cancellation } \\
\text { with compressive sensing }\end{array}$ & $\begin{array}{l}\text { SNR, compression } \\
\text { ratio, better } \\
\text { reconstruction. }\end{array}$ & $\begin{array}{l}\text { Less effective } \\
\text { benchmarking }\end{array}$ \\
\hline $\begin{array}{l}\text { Zhou [52]- } \\
\quad 2013\end{array}$ & $\begin{array}{l}\text { Compressed sensing of speech } \\
\text { signals }\end{array}$ & $\begin{array}{l}\text { K-Singular Value } \\
\text { Decomposition, orthogonal } \\
\text { matching pursuits }\end{array}$ & $\begin{array}{l}\text { SNR, Perception } \\
\text { evaluation of speech } \\
\text { quality, mean opinion } \\
\text { score }\end{array}$ & $\begin{array}{l}\text { Less effective } \\
\text { benchmarking }\end{array}$ \\
\hline
\end{tabular}

\section{RESEARCH GAP}

From the previous section, it can be seen that existing studies towards implementing compressive sensing on signal processing do exists with advantages as well as limitations too. However, a closer look into the studies being performed till date was found with an obvious research gap. Brief discussions of some of them are:
- Less Effective Survey work: Our investigation shows that there are 45 survey papers in the area of compressive sensing, where we choose to review the best 16 papers. It was found that majority of the survey paper are more inclined towards discussing the theoretical aspects, which are highly repetitive in all the other survey papers 
too. Another issue we came across is the survey papers till date has very less discussion of prior research contribution and an attempt to excavate its effectiveness by exploring either comparative analysis or by exploring research gap.

- Less focus on Reconstruction: All the experimental based research papers have emphasized on implementing compressive sensing and quite less focus on its outcome with respect to complexities associated with reconstructed signals. Although reconstruction phenomenon is well defined in image signals, but importance of it is found few in video and speech signals. A closer look into the tabulated information will show that frequently used algorithms are projectionbased, orthogonal matching pursuits, least absolute shrinkage and selection operator etc. However, the researchers have overlooked that although such techniques sometimes yield faster processing, but none of the above discussed technique can be wisely adopted for reconstruction of a video signal.

- Ambiguity in implementing Sparsity matrix: Majority of the studies till date have considered sparsity as the image size, which will mean that when the image is divided into smaller sizes (like sub-images), the quantity of the samples will be required to be higher in size for the purpose of performing reconstruction of an image. However, adoption of such techniques drastically minimizes the probability of adopting compressive sensing with present definition of sparsity matrix in realtime.

- Clear tradeoff in image and video: As discussed earlier in this paper that as the signal properties of image, video, and speech quite differs from each other, so a generalized algorithm for compressive sensing cannot be directly applied to all of these signals. One of the significant problems in implementing compressive sensing and its encoding standards on the image signal is less effective compression which is quite poor when compared with video compression techniques.

- Less Focus on networking aspects: The area of compression arises from networking itself, particularly the wireless one. Although there are some of the research papers which has considered choosing to investigate compressive sensing in wireless sensor network, but such studies have not focused on original network parameters e.g. number of nodes, node ID, transmission region, channel state information (scattering, fading, interference, noise), mobility aspects, signal attenuation, physical configurations of the nodes etc. It is much required to study compressive sensing from networking viewpoint as it gives better applicability in real-time.

\section{CONCLUSION}

The present paper have studied about the effectiveness of existing compressive sensing algorithms that has been seen to have maximized interest in most recent times in signal processing. The phenomenon of compressive sensing works in completely different way as compared to Nyquist principle. The study of compressive sensing must be more encouraged although there are some studies being done. We propose the justification for this fact as - in real time, there are many situations where the sampling rate of the data is highly limited either owing to information capturing devices to slow processing of the signals. Hence, the applications of compressive sensing can be highly adopted in such scenario. For ensuring the information content of this article, we have adopted only the ISI index manuscript to showcase the extent and effectiveness of the studies being done till date. However, we can say that studies towards compressive sensing on speech signals are quite less as there is no ISI index journal to discuss about it, we have come across non-ISI indexed journals to discuss about speech signals. Hence, it can be said that studies towards compressive sensing is quite less and more should be encouraged to enhance the applicability of the studies towards compression. Our future work will be to address the research gap and limitations that are explored in the existing studies towards compressive sensing. Our future direction of the study will be to evolve up with a transmitter and receiver node with establishment of wireless signaling properties of wireless network and perform analysis of the compressive sensing in the present of various real time networking constraints as well as various impediments towards successful compressive sensing and reconstruction, and also in order to obtain lossless kind of reconstruction even to the neighbor region to diagnostically important region, an approach of compressed sensing is assumed to be considered as the next work towards having image compression and transmission through highly resource constraints TCP/IP and other networks.

\section{REFERENCES}

[1] A. N. Ali, C. C. Menard, "Compression of Biomedical Images and Signals”, John Wiley \& Sons, Science, 2013.

[2] S. Foucart, H. Rauhut, "A Mathematical Introduction to Compressive Sensing", Springer Science \& Business Media, Electronic books - 643 pages, 2013.

[3] Z. Han, H. Li, W. Yin, "Compressive Sensing for Wireless Networks", Cambridge University Press, Computers-293 pages, 2013.

[4] C. R. Berger, Z. Wang, J. Huang, and S. Zhou, "Application of Compressive Sensing to Sparse Channel Estimation" IEEE Communication Magazine, pp.164$174,2010$.

[5] A. Gilbert, P. Indyk, "Sparse Recovery Using Sparse Matrices", Proceedings of IEEE, pp.937-947, Vol.98, Iss.6, 2010.

[6] L.C. Potter, E. Ertin, J. T. Parker, M. Cetin, "Sparsity and Compressed Sensing in Radar Imaging", Proceedings of the IEEE, Vol. 98, No. 6, June 2010.

[7] J.A. Tropp, S. J. Wright, "ComputationalMethods for Sparse Solution of Linear Inverse Problems", Proceedings of the IEEE, Vol. 98, No. 6, June 2010.

[8] V. M. Patel, R. Chellappa, "Sparse Representations, Compressive Sensing and Dictionaries for Pattern Recognition”, IEEE-First Asian Conference on Pattern Recognition, pp.325-329, 2011.

[9] G. Wang, "Compressive Sensing for Biomedical Imaging", IEEE Transactions on Medical Imaging, vol. 30, no. 5, May 2011

[10] U. Dias, M. Rane, S. R. Bandewar, "Survey of Compressive Sensing", International Journal of Scientific \& Engineering Research, Vol.3, Iss.2, February-2012.

[11] A. Mammeri, B. Hadjou, and A. Khoumsi, "A Survey of Image Compression Algorithms for Visual Sensor 
Networks", International Scholarly Research Network, Article ID 760320, 19 pages, 2012.

[12] K. Hayashi, M. Nagahara, T. Tanaka, "A user's guide to Compressed Sensing for Communication Systems", IEICE Transactions of Communications, Vol.96, No.3, 2013.

[13] J. Kaur, K. Kaur, M. Bharti, P. Sharma and J. Kaur, "Reconstruction Using Compressive Sensing: A Review", International Journal of Advanced Research in Computer and Communication Engineering, Vol. 2, Iss.9, September 2013.

[14] J. Ender, "A Brief Review of Compressive Sensing Applied to Radar", 14th International radar Symposium, 2013.

[15] S. Pudlewski and T. Melodia, "A Tutorial on Encoding and Wireless Transmission of Compressively Sampled Videos", IEEE Communications Surveys \& Tutorials, Vol. 15, No. 2, Second Quarter 2013

[16] S. Qaisar, R. M. Bilal, W. Iqbal, M. Naureen and S. Lee, "Compressive Sensing: From Theory to Applications, A Survey", IEEE-Journal of Communication and Network, vol.15, Iss.5, pp.443-456, 2013.

[17] R. Subban, S. Guria, P.Pasupathi, S.Muthukumar, "Realtime Compressive Tracking - A Study and Review", International Journal of Emerging Technologies in Computational and Applied Sciences, 2014.

[18] Q. Zhou and L. Zhou, "Compressive Sensing for Video Coding: A Brief Overview", IEEE COMSOC MMTC ELetter, Vol.9, No.2, March 2014.

[19] A. Ali, "Localization through compressive sensing: A survey", International Journal of Wireless Communications and Mobile Computing, 2015.

[20] Bing Han, Feng Wu, Dapeng Wu, "Image representation by compressed sensing", Image Processing, 2008. ICIP 2008, 15th IEEE International Conference on , vol., no., pp.1344-1347, 12-15 Oct. 2008.

[21] Shiqian Ma, Wotao Yin, Yin Zhang, Chakraborty, A., "An efficient algorithm for compressed MR imaging using total variation and wavelets", Computer Vision and Pattern Recognition, 2008, CVPR 2008, IEEE Conference on , vol., no., pp.1-8, 23-28 June 2008.

[22] Nagesh P, Baoxin Li, "A compressive sensing approach for expression-invariant face recognition", Computer Vision and Pattern Recognition, 2009, CVPR 2009, IEEE Conference on, vol., no., pp.1518-1525, 20-25 June 2009.

[23] Schulz A, Velho L, da Silva E.A.B., "On the empirical rate-distortion performance of Compressive Sensing," Image Processing (ICIP), 2009 16th IEEE International Conference on, vol., no., pp.3049-3052, 710 Nov. 2009.

[24] Wright J, Yang A.Y, Ganesh A, Sastry S.S, Yi Ma, "Robust Face Recognition via Sparse Representation", Pattern Analysis and Machine Intelligence, IEEE Transactions on, vol.31, no.2, pp.210-227, Feb. 2009.

[25] Junfeng Yang, Yin Zhang, Wotao Yin, "A Fast Alternating Direction Method for TVL1-L2 Signal Reconstruction From Partial Fourier Data," Selected
Topics in Signal Processing, IEEE Journal of, vol.4, no.2, pp.288-297, April 2010.

[26] Sen P, Darabi S, "Compressive Rendering: A Rendering Application of Compressed Sensing," Visualization and Computer Graphics, IEEE Transactions on , vol.17, no.4, pp.487-499, April 2011.

[27] Chen Jing, Yongtian Wang and Hanxiao Wu. "A coded aperture compressive imaging array and its visual detection and tracking algorithms for surveillance systems." Sensors 12, no. 11, pp.14397-14415, 2012.

[28] Sermwuthisarn, Parichat, SupatanaAuethavekiat, DuangratGansawat, and VorapojPatanavijit. "Robust reconstruction algorithm for compressed sensing in Gaussian noise environment using orthogonal matching pursuit with partially known support and random subsampling", Springer-EURASIP Journal on Advances in Signal Processing 2012, no. 1, pp.1-21, 2012.

[29] Hemalatha R, Radha S, Raghuvarman N, Soumya B, and Vivekanandan B, "Energy Efficient Image Transmission over Bandwidth Scarce WSN using Compressed Sensing", International Conference on IT and Intelligent Systems (ICITIS'2013), Penang (Malaysia), pp.57-61, 28-29th August 2013.

[30] Yipeng Liu, De Vos M, Gligorijevic I, Matic V, Yuqian Li, Van Huffel S., "Multi-structural Signal Recovery for Biomedical Compressive Sensing," Biomedical Engineering, IEEE Transactions on, vol.60, no.10, pp.2794-2805, Oct. 2013.

[31] Pudlewski S, Melodia T, "On the Performance of Compressive Video Streaming for Wireless Multimedia Sensor Networks," Communications (ICC), 2010 IEEE International Conference on, vol., no., pp.1-5, 23-27 May 2010.

[32] Zhang Chaozhu, Leng Jing, "Distributed video coding based on compressive sensing," Multimedia Technology (ICMT), 2011 International Conference on, vol., no., pp.3046-3049, 26-28 July 2011.

[33] Pudlewski S, Melodia T., "A Rate-Energy-Distortion Analysis for Compressed-Sensing-Enabled Wireless Video Streaming on Multimedia Sensors," Global Telecommunications Conference (GLOBECOM 2011), 2011 IEEE , vol., no., pp.1-6, 5-9 Dec 2011.

[34] Mansour H, Yilmaz O., "Adaptive compressed sensing for video acquisition," Acoustics, Speech and Signal Processing (ICASSP), 2012 IEEE International Conference on, vol., no., pp.3465-3468, 25-30 March 2012.

[35] Sankaranarayanan A.C, Studer C, Baraniuk R.G., "CSMUVI: Video compressive sensing for spatialmultiplexing cameras," Computational Photography (ICCP), 2012 IEEE International Conference on, vol., no., pp.1-10, 28-29 April 2012.

[36] Hua Chen, Anhong Wang, Xiaoli Ma, "An Improved Wireless Video Multicast Based on Compressed Sensing", Intelligent Information Hiding and Multimedia Signal Processing, 2013 Ninth International Conference on , vol., no., pp.582-585, 16-18 Oct. 2013.

[37] Pudlewski S, Melodia T., "Compressive Video Streaming: Design and Rate-Energy-Distortion 
Analysis", Multimedia, IEEE Transactions on, vol.15, no.8, pp.2072-2086, Dec. 2013.

[38] Pudlewski S, Melodia T., "RA-CVS: Cooperating at low power to stream compressively sampled videos", Communications (ICC), 2013 IEEE International Conference on, vol., no., pp.1821-1826, 913 June 2013.

[39] Yuan Xin, Jianbo Yang, Patrick Llull, Xuejun Liao, Guillermo Sapiro, David J. Brady, and Lawrence Carin. "Adaptive temporal compressive sensing for video", arXiv preprint arXiv: 1302.3446, Oct.2013.

[40] Ying Liu, Ming Li, Pados, D.A., "Motion-Aware Decoding of Compressed-Sensed Video", Circuits and Systems for Video Technology, IEEE Transactions on, vol.23, no.3, pp.438-444, March 2013.

[41] Michael Iliadis, Jeremy Watt, Leonidas Spinoulas, Aggelos K. Katsaggelos,"Video Compressive SensinguUsing Multiple Measurement Vectors", IEEE International Conference on Image processing(ICIP), pp.136-140, 15-18 Sept. 2013.

[42] Giacobello. D, Christensen M.G, Murthi M.N, Jensen S.H, Moonen M., "Retrieving Sparse Patterns Using a Compressed Sensing Framework: Applications to Speech Coding Based on Sparse Linear Prediction," Signal Processing Letters, IEEE, vol.17, no.1, pp.103-106, Jan. 2010.

[43] Christensen M.G, Stergaard J, Jensen S.H., "On compressed sensing and its application to speech and audio signals", Signals, Systems and Computers, 2009 Conference Record of the Forty-Third Asilomar Conference on , vol., no., pp.356-360, 1-4 Nov. 2009.

[44] Bruno Masiero and Martin Pollow, "A Review of the Compressive Sampling Framework in the Lights of Spherical Harmonics: Applications to Distributed Spherical Arrays", Proc. of the 2nd International Symposium on Ambisonics and Spherical Acoustics, Paris, France, 6-7 May 2010.

[45] Anthony Griffin, EleniKaramichali and AthanasiosMouchtaris, "Speaker Identification using
Sparsely Excited Speech Signals and Compressed Sensing", 18th European Signal Processing Conference (EUSIPCO-2010), Aalborg, Denmark, pp.1444-1448, 23-27 August 2010.

[46] Asaei A, Bourlard H, Cevher V., "Model-based compressive sensing for multi-party distant speech recognition", Acoustics, Speech and Signal Processing (ICASSP), 2011 IEEE International Conference on , vol., no., pp.4600-4603, 22-27 May 2011.

[47] Qun Feng Tan, Georgiou P.G, Narayanan S., "Enhanced Sparse Imputation Techniques for a Robust Speech Recognition Front-End", Audio, Speech, and Language Processing, IEEE Transactions on, vol.19, no.8, pp.2418-2429, Nov. 2011.

[48] Yue Wang, ZhixingXu, Gang Li, Liping Chang, Chuanrong Hong, "Compressive sensing framework for speech signal synthesis using a hybrid dictionary", Image and Signal Processing (CISP), 2011 4th International Congress on , vol.5, no., pp.2400-2403, 15-17 Oct. 2011.

[49] Xu Feng, Wang Xia, Zheng Xiao-Dong, Wang Hao, " An Adaptive Compressed Sensing Method in Speech", International Journal of Advancements in Computing Technology(IJACT), Vol.4, no.8, May 2012.

[50] Ahmed A. Hashim, "Sub-Nyquist Frequency Efficient Audio Compression", Al-Khwarizmi Engineering Journal, Vol. 8, no.3, pp.53- 62, March 2012.

[51] Kuei-Hong Lin, Cheng-Hsun Lin, Kuo-Huang Chung and Kai-Shun Lin, "A Compressive Sensing-based Speech Signal Processing System for Wearable Computing Device in IPTV Environment", 3rd International conference on Multimedia Technology(ICMT-2013), pp.1547-1551, November 2013.

[52] Yan Zhou, Heming Zhao, "Speech Signal Compressed Sensing Based on K-SVD Adaptive Dictionary", Journal of Theoretical and Applied Information Technology, Vol.48, no.2, 20th February 2013. 